\title{
Product Label Reading System for Blind People using Support Vector Machine Algorithm
}

\author{
S. Jeyapriyanga, S. P. Priyadharshini, Sangeetha $S$
}

\begin{abstract}
Theoretical-This paper shows a camera based assistive content perusing of item marks from articles to support outwardly tested individuals. Camera fills in as fundamental wellspring of info. To recognize the items, the client will move the article before camera and this moving item will be identified by Background Subtraction (BGS) Method. Content district will be naturally confined as Region of Interest (ROI). Content is extricated from ROI by consolidating both guideline based and learning based technique. A tale standard based content limitation calculation is utilized by recognizing geometric highlights like pixel esteem, shading force, character size and so forth and furthermore highlights like Gradient size, slope width and stroke width are found out utilizing SVM classifier and a model is worked to separate content and non-content area. This framework is coordinated with OCR (Optical Character Recognition) to extricate content and the separated content is given as a voice yield to the client. The framework is assessed utilizing ICDAR-2011 dataset which comprise of 509 common scene pictures with ground truth.
\end{abstract}

Keywords: Moving object detection, Background subtraction method, Text localization, SVM classifier, Optical character Recognition (OCR)

\section{INTRODUCTION}

Arumalla Raja et al. [1] presents a camera-based mark peruser to help daze people to peruse names of names on the items. This uses open cv library to isolate the marks from images.The got name is then changed over to content by utilizing tesseract library. The following stage is to change over to discourse it utilizes a flite library. As indicated by a study of World Health Organization(WHO) 2014[2], the estimation states that 285 million individuals are outwardly impeded around the world (39 million are visually impaired and 246 have low vision). Indeed, even in created nations like United States(US), 60,393 understudies are outwardly tested. These rates have expanded quickly over years. Around $90 \%$ of outwardly impeded individuals lead their lives in creating nations [2]. Late research works are done in creating braille character acknowledgment, computerized camera and versatile cameras which help visually impaired individuals in their everyday life. Presently outwardly tested individuals are denoting their accomplishment in practically all fields with

Revised Manuscript Received on August 22, 2019.

S.Jeyapriyanga, Department of Computer science and Engineering, Bharath Institute of Higher Education and Research, Chennai, Tamilnadu, India. Email: priyankashanmugam16@gmail.com

S.P.Priyadharshini, Department of Computer science and Engineering, Bharath Institute of Higher Education and Research, Chennai, Tamilnadu, India. Email: spriya07.cse@gmail.com

Sangeetha S, Department of Computer science and Engineering, Bharath Institute of Higher Education and Research, Chennai, Tamilnadu, India. Email: sangeethasathya01@gmail.com the assistance of advanced improvement.

Perusing is a fundamental part in the present focused world. Everything around us are as reports, receipts, bank

explanations, item bundles, café menus and so forth. There are not many individual associates to help item name perusing and record perusing to support outwardly tested individuals and those item read the content to the client in type of voice[1],[3],[5]. For example on considering the Braille Character Recognition (BCR),it perceives the braille characters and understands it out to the client and even there are compact standardized identification perusers to distinguish different data about the item. One noteworthy disadvantage with these sort of gadgets is that the outwardly tested individuals can't find the scanner tag independent from anyone else. Some framework coordinates OCR to perceive words and give a voice yield. To conquer the weakness of finding the district of intrigue (ROI) consequently, we propose a movement recognition calculation to find ROI. For example, in a general store situation if the client has to realize what item he/she is holding, he needs to remove content from the item however the significant inadequacy is the framework will separate all content even from the foundation. So as to keep away from that, an individual will move the article before the camera which will be identified by movement recognition calculation. It is a very provoking errand to naturally confine Region of Interest (ROI) from complex foundation as the article is moving. Henceforth the moving article will be followed all through and in the last outline the moving item will be recognized, given that the item must be still at any rate for a few seconds towards the end.

There are two strategies to separate content from the item rule based and learning based systems. Principle Based Techniques utilizes just the geometric properties of the pictures like pixel esteem, Color power, Character size, perspective ratio, Color consistency crosswise over content and so forth to identify [5]

Chucai Yi et al. [11] expanded the learning calculation via preparing extra element like Stroke segments. Here a novel calculation dependent on stroke parts and illustrative Gabor channels, is utilized to recognize content districts in common scene pictures. The stroke segments are found out to characterize content and k-mean calculation to order. Gabor channel is utilized for content identification.Text can be displayed as a blend of stroke parts with an assortment of directions, and highlights of content can be extricated from mixes and dispersions of the 
stroke segments.

Learning based systems uses AI calculation to recognize content locale from non-content district. A model is fabricated dependent on numerous highlights like Gradient extent, slope width and stroke width which are sufficient to separate both content and non-content locale. [7]

\section{RELATED WORK}

Arumalla Raja et al. [1] presents a camera-based label reader to help blind persons to read names of labels on the products. This uses open cv library to separate the labels from images[14],[16],[18].The received label is then converted to text by using tesser act library. The next step is to convert to speech it uses a flite library. As the whole system which is implemented here is hardware oriented and using libraries, it is very costly to afford.

According to a survey of World Health Organization(WHO) 2014[2], the estimation states that285 million people are visually impaired worldwide (39 million are blind and 246 have low vision). Even in developed countries like United States(US), 60,393 students are visually challenged. These rates have increased rapidly over years. Approximately $90 \%$ of visually impaired people lead their lives in developing countries [2]. Recent research works are done in developing braille character recognition, digital camera and portable cameras which assist blind people in their daily life. Presently visually challenged people are marking their achievement in almost all fields with the help of digital improvement.

In order to eliminate the background from the object, background subtraction algorithm [4] is applied. Initially video sequence is converted to frames and each frame is processed separately. Background subtraction is a method which involves computational vision process of extracting foreground objects in a particular scene[13],[15],[17]. A foreground object can be described as an object of attention which helps in reducing the amount of data to be processed as well as provide important information to the task under consideration. Background is estimated using "Mean filtering" i.e., the background frame is estimated using the mean pixel values of $n$ frames.

Color-based text segmentation [5] is performed through a Gaussian mixture model for calculating a confidence value for text regions. This type of algorithm tries to define a universal feature descriptor of text[8],[10],[12]. Text characters will have smaller width and height than its background and the color uniformity will be same to certain extend. Edge is the distinct characteristic which can be used to find possible text areas. Text is mainly composed of the strokes in horizontal, vertical, up-right, up-left direction, so it can be considered that the region with higher edge strength in these directions is the text region.

\section{SYSTEM ARCHITECTURE}
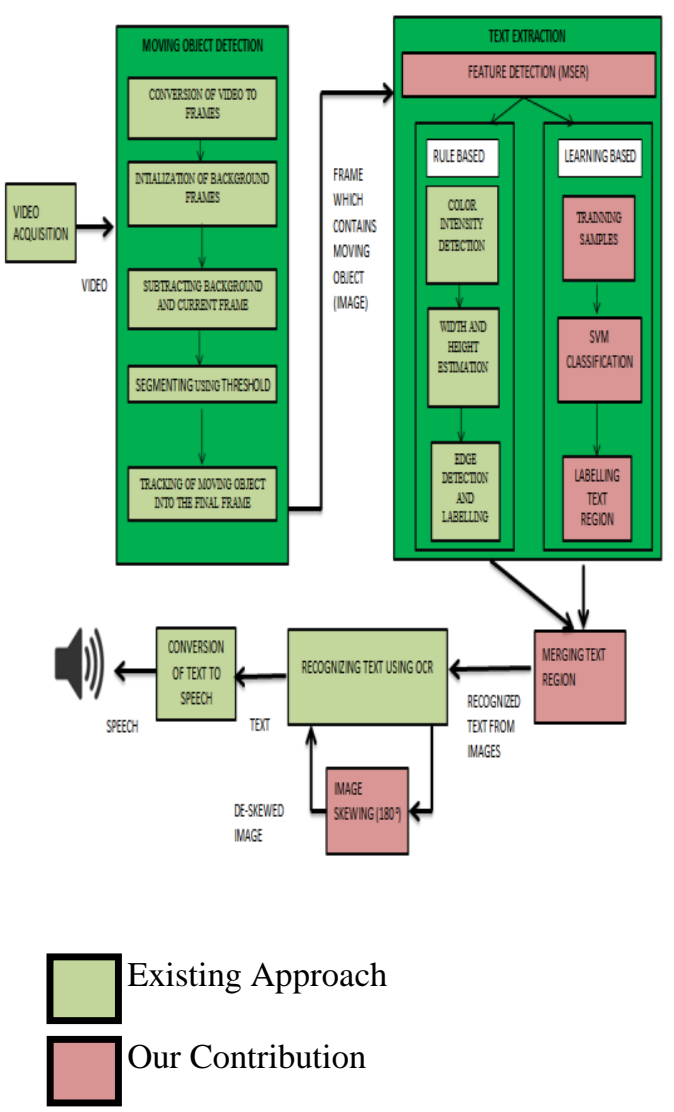

Figure 1 - Overall Architecture

\section{A. Video Acquisition}

The constant video is caught with the assistance of a camera. The video should keep going for in any event 5 seconds and so as to separate content from the item it ought to be still at any rate in the last frame, hence the client keeps the article still for 2 seconds at the end[9]. The moving article is followed and recognized by drawing the bouncing box in the last outline[7],[9],[11].

\section{B. Moving object Detection}

So as to dispose of the foundation from the article, foundation subtraction calculation [4]isapplied.Initially video arrangement is changed over to outlines and each edge is handled independently. Foundation subtraction is a technique which includes computational vision procedure of removing frontal area protests in a specific scene. A closer view article can be portrayed as an object of consideration which aides in diminishing the measure of information to be handled just as give significant data to the assignment under thought[2],[4],[6]. Foundation is evaluated utilizing "Mean separating" i.e., the foundation casing is assessed utilizing the mean pixel estimations of $\mathrm{n}$ outlines.

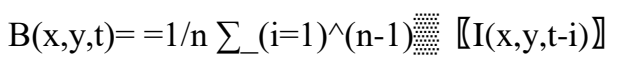


When the foundation edge is fixed, the present casing pixel worth is subtracted from the instated foundation outline. Contrast an incentive above edge is evaluated to be the moving pixel. The key paramater in thresholding procedure is the decision of edge esteem. Limit esteem which is too high neogiates moving item and edge esteem which is too low includes many article which isn't moving, henceforth it ought to be an ostensible worth which is around 50[3]

Contrast $=\mathrm{I}(\mathrm{x}, \mathrm{y}, \mathrm{t})-\mathrm{B}(\mathrm{x}, \mathrm{y}, \mathrm{t})>$ Threshold

Moving item is totally followed and the moving pixels are at long last distinguished in the last outline and a bouncing is drawn over the moving article. The casing which has the distinguished moving item is send to the following stage.
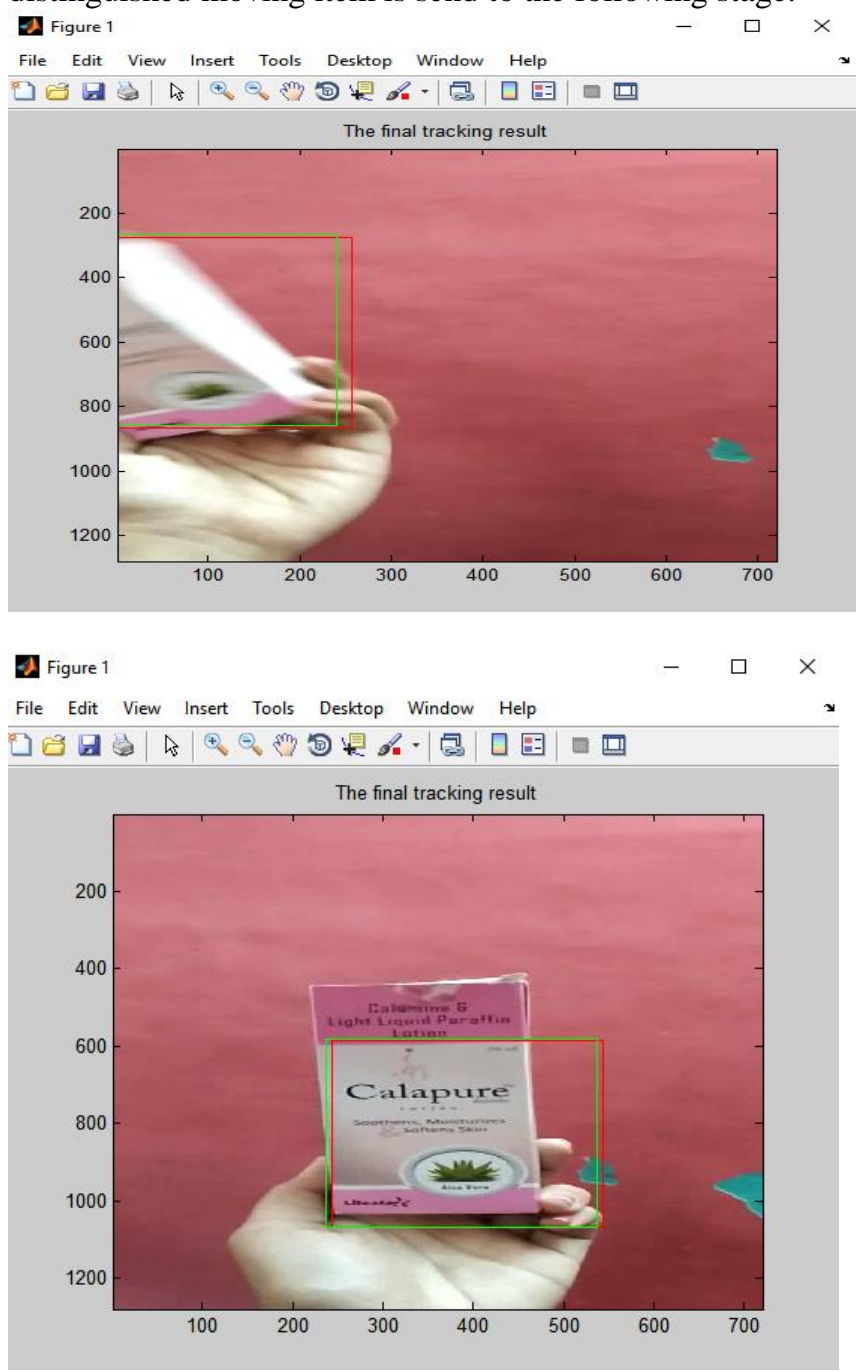

Figure- 2 Moving Object Detection

\section{Content Extraction}

The framework manufactures a programmed content restriction and extraction framework which can acknowledge various kinds of still pictures (or video outlines) potentially with a mind boggling foundation. Content extraction joins both principle based and learning-based procedures to limit content area.

\section{Feature recognition}

Maximally Stable Extremal Region (MSER) [13] is a strategy for mass recognition in pictures. The MSER calculation extricates from a picture various co-variation locales, called MSERs: a MSER is a stable associated part of some dark level arrangements of the image. MSER removes districts which stay almost the equivalent through a wide scope of limits. Every one of the pixels underneath a given limit are white and each one of those above or equivalent are dark. In a succession of thresholded pictures It with outline $t$ comparing to edge $t$, at first dark picture shows up. After that white spots relating tolocal power minima will in general show up and afterward become bigger. These white spots will in the long run converge, until the entire picture is white. The arrangement of every single associated part in the succession is the arrangement of all extremalregions. Elliptical edges are appended to the MSERs by fitting circles to the districts. Those districts descriptors are kept as features.The word extremal alludes to the property that all pixels inside the MSER have either higher (brilliant extremal locales) or lower (dim extremal areas) force than every one of the pixels on its external limit. The component identifier finds both content and non-content area. Further content is removed from these recognized MSER locale.

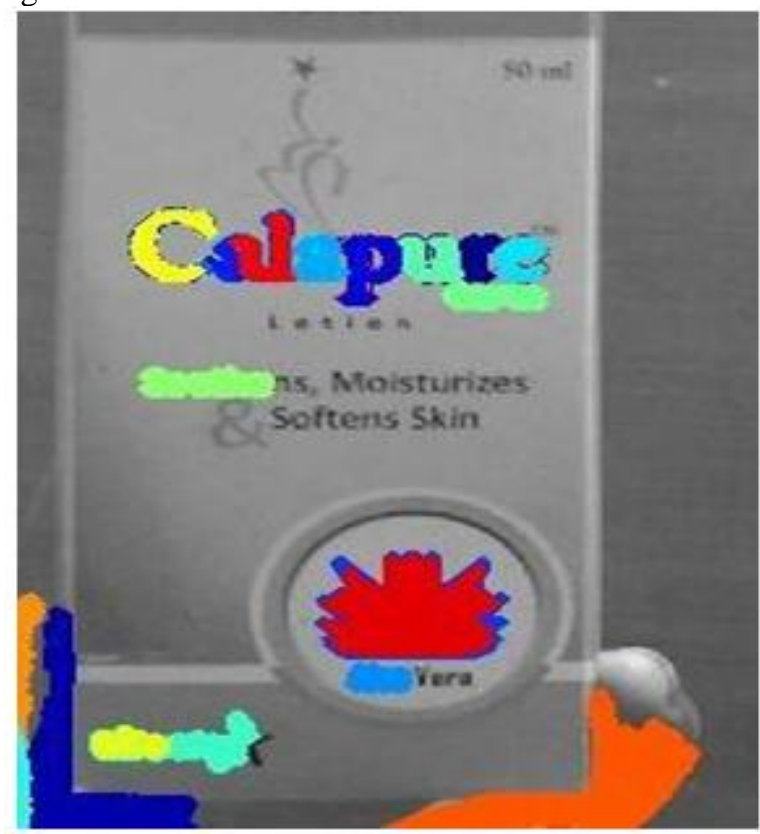

Figure - 3 Detected feature using MSER

\section{Rule-Based Text Extraction}

Picture parcel is first performed to assemble pixels that have a place with a similar content character, acquiring a double guide of up-and-comer character segments for extricating content data from a complex background,.Rule-based calculations separate content data from predefined content designs, for example, character size, perspective proportion, edge thickness, character structure, shading consistency of content string, etc[13,24] for applying pixel-level picture handling to. In our framework the properties which are thought about are Color power, Width and Height and Edge. Shading based content division [5] is performed through a Gaussian blend model for figuring a confidence esteem for content districts.

This sort of calculation
attempts to define a
Published By:
Blue Eyes Intelligence Engineering
\& Sciences Publication


widespread element descriptor of content. Content characters will have littler width and tallness than its experience and the shading consistency will be same to certain expand. Edge is the particular trademark which can be utilized to discover conceivable content territories. Content is principally made out of the strokes in flat, vertical, up-appropriate, up-left course, so it tends to be viewed as that the area with higher edge quality in these ways is the content locale. We utilize the edge finder to get the edge maps in four directions.Canny edge identifier is utilized to get edge image[7].

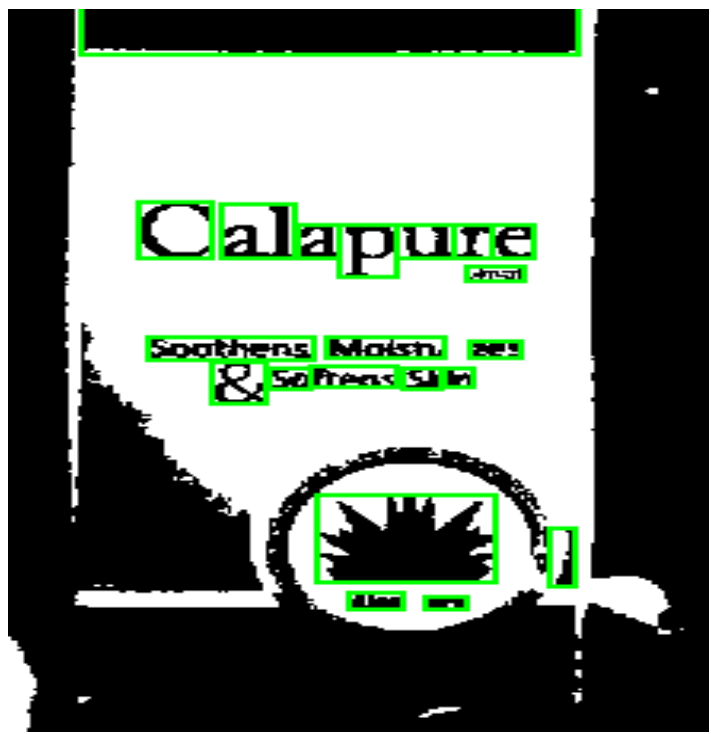

Figure -4 Rule Based Result

\section{Learning-Based Text Extraction}

Indeed, even the standard based content Extraction can identify some non-content area furthermore. To improve the exhibition of the framework we incorporate the outcomes with learning-based system which uses AI calculation (Support Vector Machine) to arrange non-content locale from content region.The proposed technique presents content discovery as a surface order issue where issue explicit information is accessible before characterization (Supervised grouping). A SVM as a trainable classifier is embraced for the surface grouping. In particular, the framework utilizes a little window to check the information picture, characterizes the pixel situated at the focal point of the window into content or non-message by breaking down its textural properties utilizing a SVM [23]. Highlights which are prepared to construct the model are Gradient extent, Gradient direction, Gradient in both even and vertical. Alongside this angle highlight edge direction, shading histogram, Stoke width change, wavelet change is likewise learned.
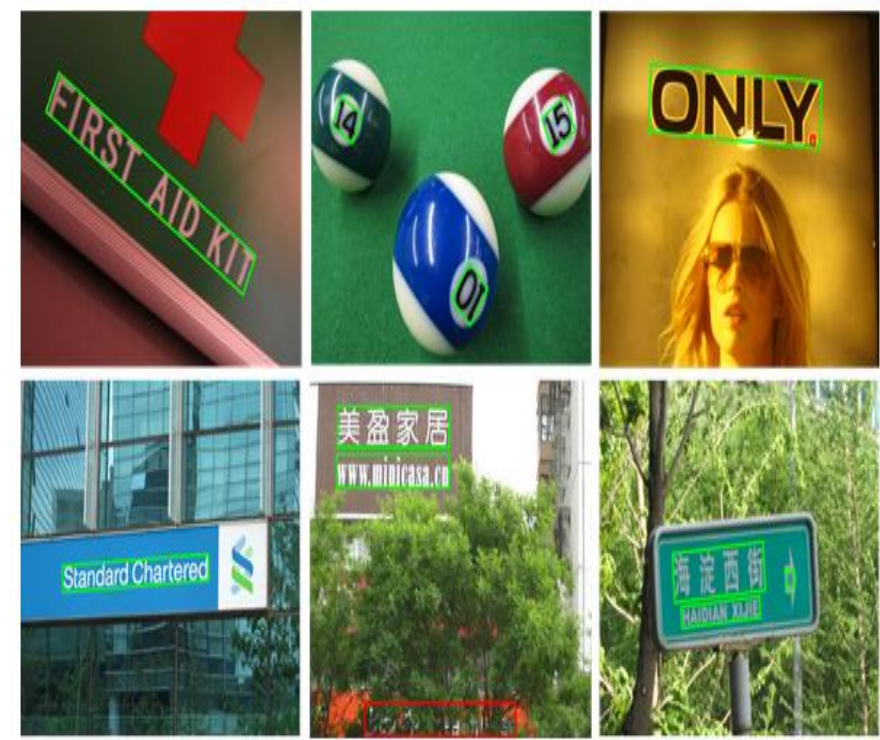

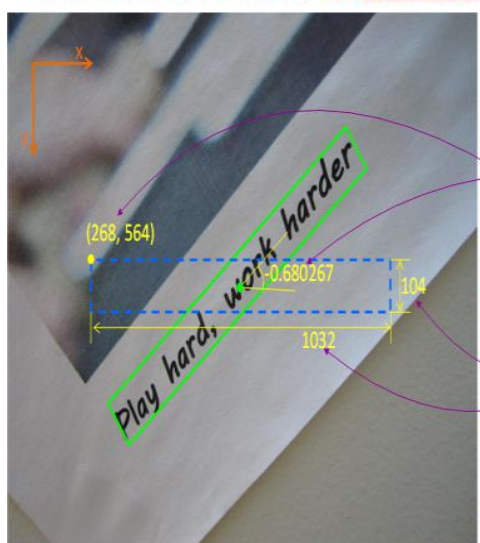

IMG_1865.JPG

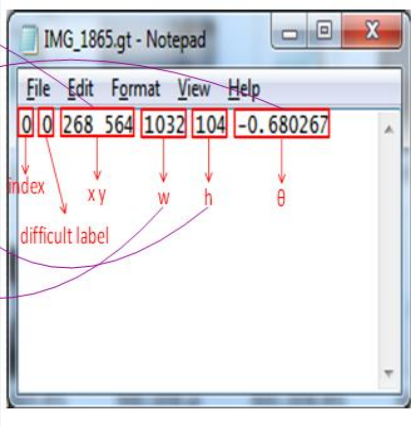

IMG_1865.gt
Figure - 5 MSRA dataset which is used to train the SVM classifier

\section{Support Vector Machine:}

SVMs have been as of late presented as a strategy for example characterization and nonlinear relapse. Given a lot of marked preparing models (xi ,yi) $\in \mathrm{RN} \times\{ \pm 1\}, \mathrm{i}=1, \ldots 1$, a SVM builds a direct classifier in a component space $\mathrm{F}$, which is nonlinearly identified with the info space by means of a guide $\phi: \mathrm{RN} \rightarrow \mathrm{F}$. The classifier is then distinguished as a standard hyperplane in $\mathrm{F}$ that effectively isolates the biggest division of information focuses, while boosting the edge between the closest models called bolster vectors (SVs)[16,23].The contribution to the SVM surface classifier originates from a $\mathrm{M} \times \mathrm{M}$ windowintheinput picture [10] where $\mathrm{M}$ is a $8 \mathrm{X} 8$ window. The indication of the SVM yield at that point speak to the class of the focal pixel in the information window. For preparing, +1 was doled out to the content class and - 1 to the non-content class. All things considered, if the SVM yield for an information example is sure, it is delegated content. Dataset which is utilized for preparing is MSRA-TD500 datasets which contains 500 regular scene pictures with ground truth.

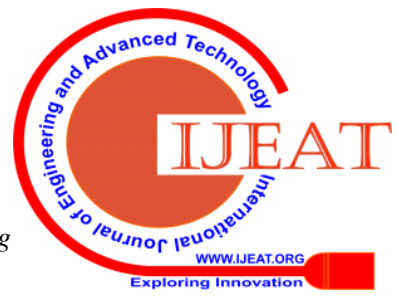




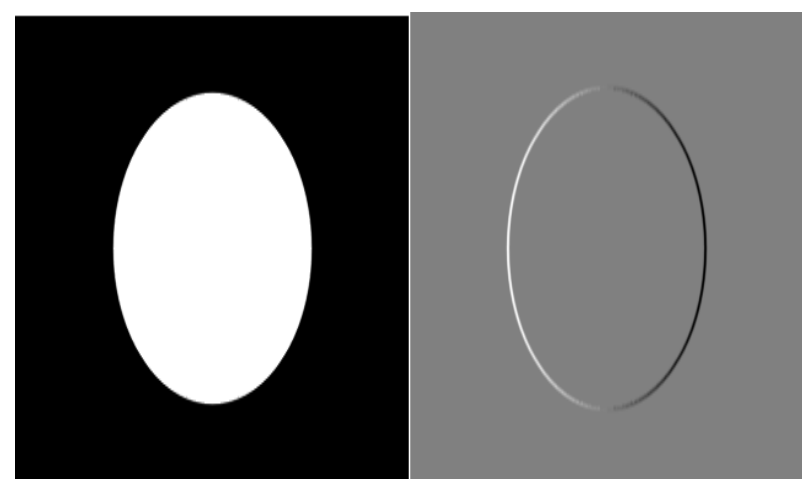

a)Original image b) Horizontal gradient

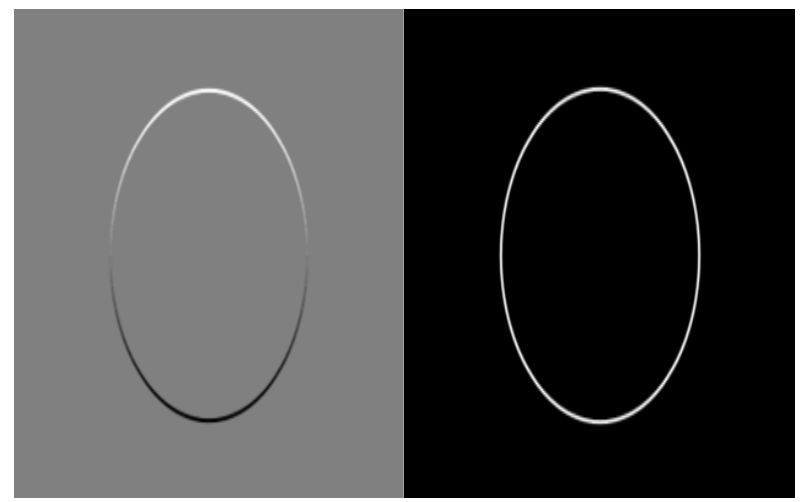

c) Vertical gradient d) Gradient Magnitude

Figure 6.- Features that are learned

Finally the text region is identified by drawing bounding boxes over the region.

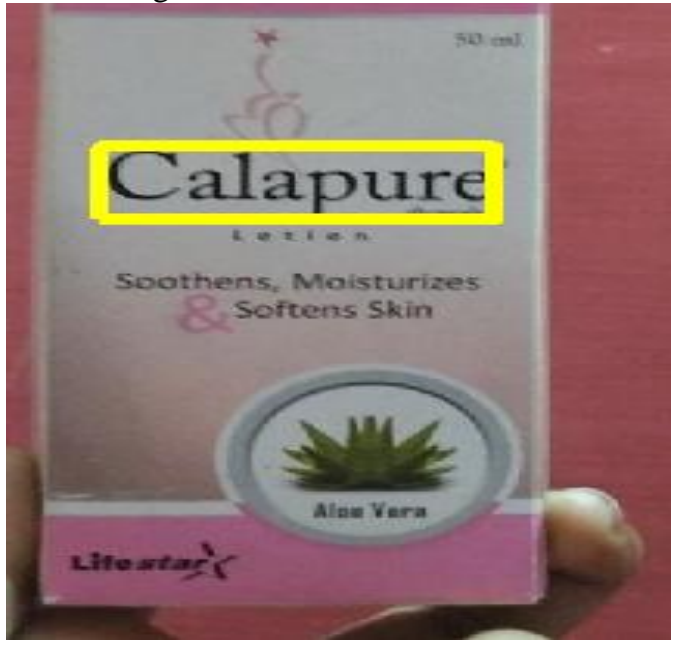

Figure 7- Learning based result

The motivation behind why joining both principle based and learning based is if the pictures isn't taken in an ideal lighting condition or in the event that the content doesn't have noticeable edges, at that point guideline based outcome will fall flat and in the event that the organization of the content is absent in informational index, at that point learning based outcome will come up short. As in [9] joins pixel-level content format examination and structure-level content component learning for higher efficiency,combining both guideline based and learning based gives higher proficiency.

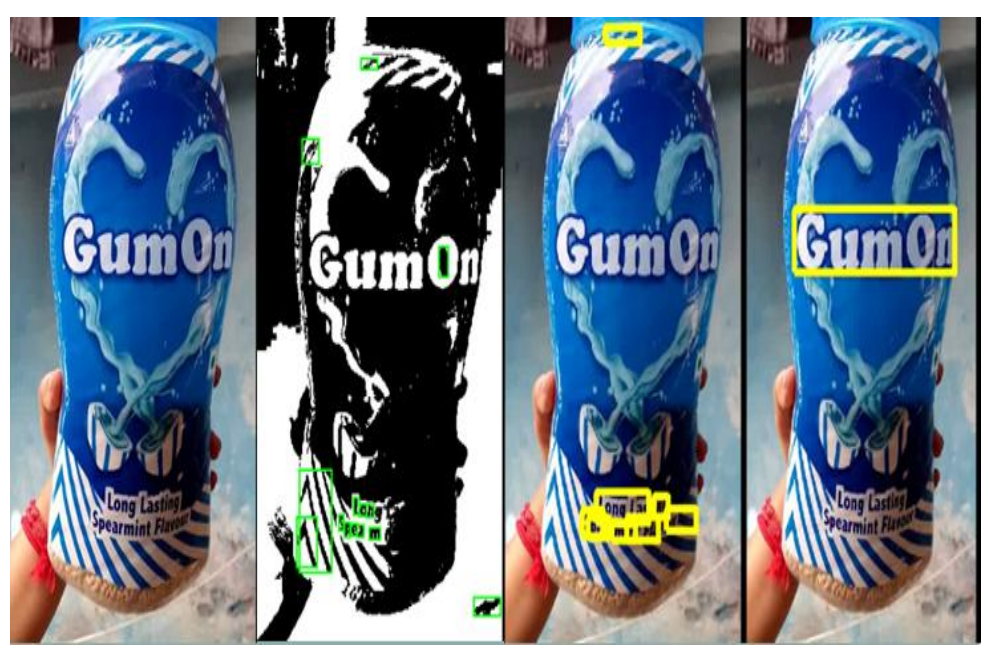

(a)Original image (b)rule based result (c)learning based result

Figure 8 - Combined Result (text detected by learning based but failed in rule based)

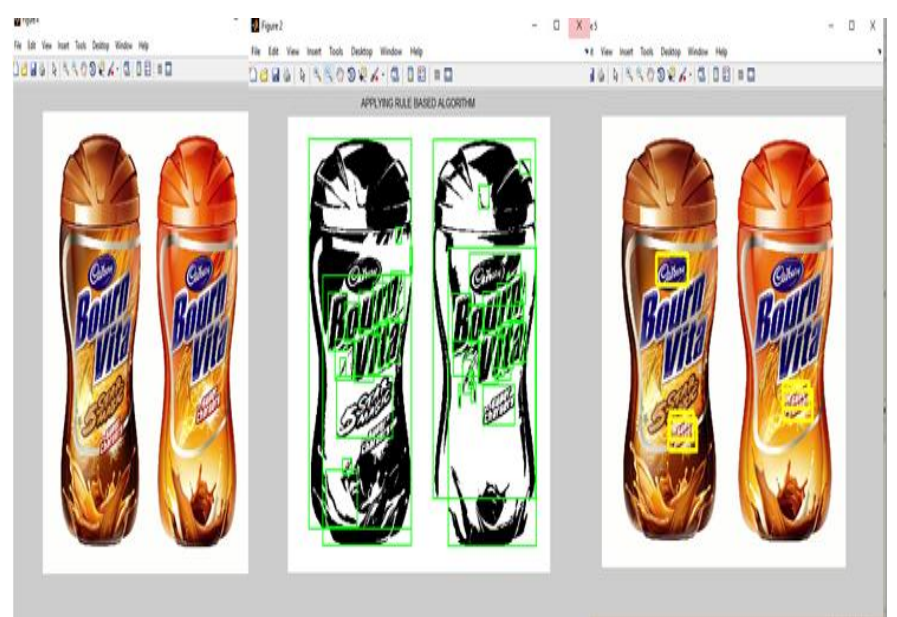

(a)Original image(b)Rule based result(c)Learning based result

Figure 9 - Combined result (text detected by rule based but failed in learning based)

\section{Image Skewing:}

The names on the item need not be in every case straight. In order to discover item names, the names ought to be made straight[19],[21],[23]. The marks might inclination or topsyturvy. Topsyturvy picture is recognized simply in the wake of making the picture to experience content acknowledgment utilizing OCR. On the off chance that the OCR transformation proportion is under $30 \%$, at that point it is turned to 1800 and again content is recognized utilizing OCR.

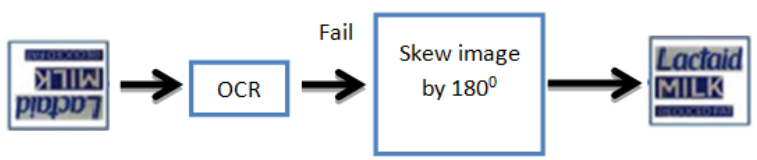

Figure 10 - Image skewing

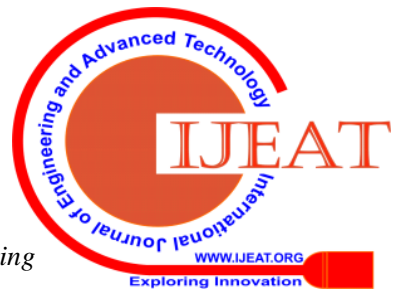




\section{Merging Text Region}

OCR works better when word is given as an info as opposed to letter [13]. So we have to discover the words from the named district. For that we utilize another strategy which structures a bouncing box for each letter which covers the neighboring letter too[20],[22],[24]. When we arrive at the part of the bargain, there will be no neighboring letter for the last letter of the word. All converging bouncing box together taken as a word and given as a contribution to the following module. A few words can be identified by both learning and managed based strategies in such case the name will be recognized twice, so as to disregard that we consolidation result by utilizing its area. On the off chance that the jumping box shows up similarly situated, at that point they will be consolidated to shape a solitary bouncing box.

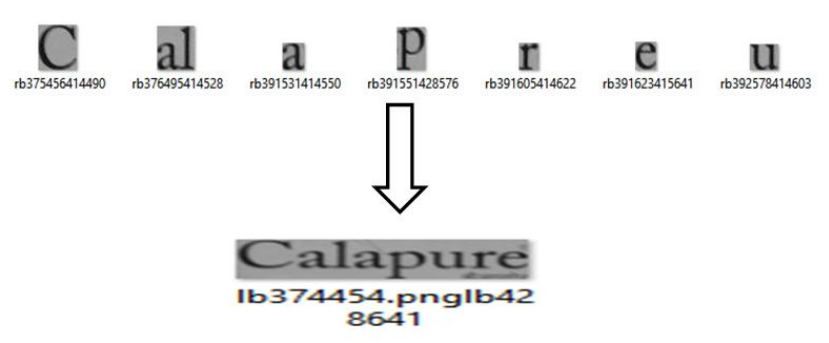

Figure 11 - Merging Text Region

\section{Text Recognition using OCR}

Optical Character Recognition or OCR is a technology that convertsimages, documents which are captured by digital camera into data which can be searched and edited. The image of the word found will be given as a input, it uses the tesseractlibrary[1] to find the word[25],[27],[29]. Tesseract is an optical character recognition engine. The converted text is then given as a speech output to the user. The text found by the OCR is converted to speech by using Microsoft SAPI.

\section{EVALUATION METRICS}

We evaluate the proposed algorithm ICDAR datasets. ICDAR 2003 Robust Reading Datasets contains 507 images in total. The image sizes range from $640 \times 480$ to $1600 \times 1200$. There are 2258 ground truth text regions in total. We evaluate the performance of our algorithm by comparing the detected text regions with the ground truth text regions. We define "precision" (p) as the ratio of total match score to the total number of localized regions and "recall" as the ratio between the total match score and the total number of ground truth regions[26],[28],[30]. Here area means the number of pixels in the image region. "f-measure" is defined as the combination of precision and the recall by the harmonic mean.

$\mathrm{r}=$ total match score / (total no. of ground truth region)

$$
\mathrm{f}=1 /(\alpha / \mathrm{p}+((1-\alpha)) / \mathrm{r})
$$

where ' $\alpha$ ' represents relative weight between the above two metrics $(\alpha=0.5)$

\begin{tabular}{|c|c|c|}
\hline SNO & METHOD & PRECISI \\
\hline 1 & Rule based & 09.52 \\
\hline 2 & Leaming based & 55.60 \\
\hline 3 & $\begin{array}{c}\text { Combining both rule } \\
\text { and leaming based results }\end{array}$ & 73.33 \\
\hline
\end{tabular}

\begin{tabular}{|r|c|c|}
\hline SNO & METHOD & $\begin{array}{l}\text { ACCURAC } \\
\text { Y }\end{array}$ \\
\hline 1 & Rule based & 12.2 \\
\hline 2 & Leaming based & 51.6 \\
\hline 3 & $\begin{array}{l}\text { Combining both rule and } \\
\text { leaming based results }\end{array}$ & 68.4 \\
\hline
\end{tabular}

Table 1. Comparison of accuracy of existing and proposed method

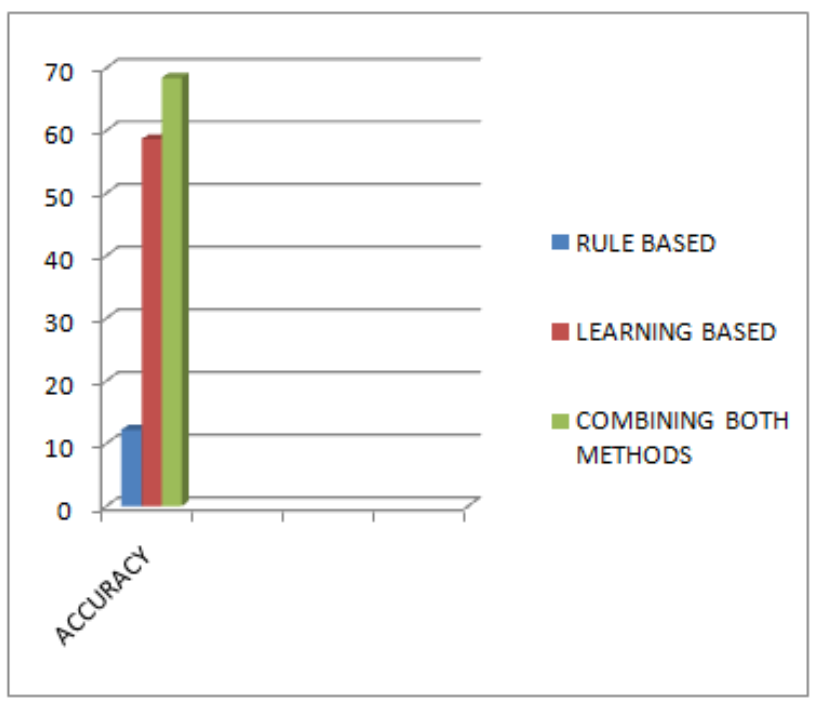

Fig. 12. Comparison of Accuracy of existing and proposed method

Figure 12 compares the accuracy of the existing and proposed method. It can be seen that accuracy increases significantly when rule based and learning based approach is combined while detecting the product label.

\begin{tabular}{|c|c|c|}
\hline SNO & METHOD & $\begin{array}{c}\text { F- } \\
\text { MEASURE }\end{array}$ \\
\hline 1 & Rule based & 13.32 \\
\hline 2 & Leaming based & 50.02 \\
\hline 3 & $\begin{array}{c}\text { Combining both rule and } \\
\text { leaming based results }\end{array}$ & 64.07 \\
\hline
\end{tabular}

Table 2. Comparison of precision of existing and proposed method 


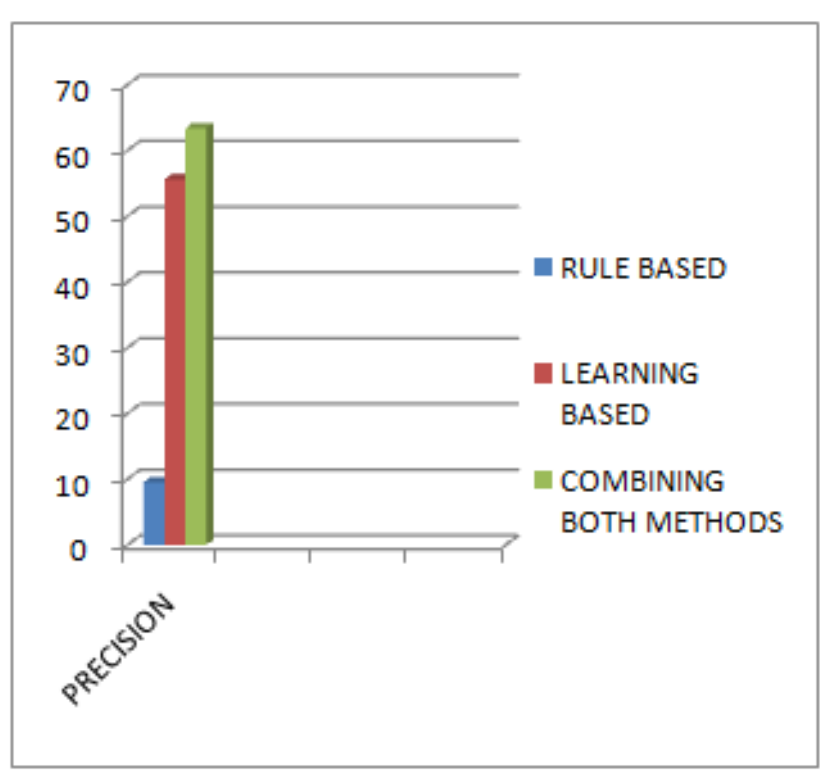

Figure - 13 Comparison of Precision of existing and proposed method

Figure 13 compares Precision of the existing and proposed method. It can be seen that precision increases significantly when rule based and learning based approach is combined while detecting the product label.

\begin{tabular}{|c|c|c|}
\hline SNO & METHOD & RECALL \\
\hline 1 & Rule based & 22.18 \\
\hline 2 & $\begin{array}{c}\text { Leaming } \\
\text { based }\end{array}$ & 45.46 \\
\hline 3 & $\begin{array}{l}\text { Combining } \\
\text { both rule and } \\
\text { leaming based } \\
\text { results }\end{array}$ \\
\hline
\end{tabular}

Table 3 - Comparison of recall of existing and proposed method

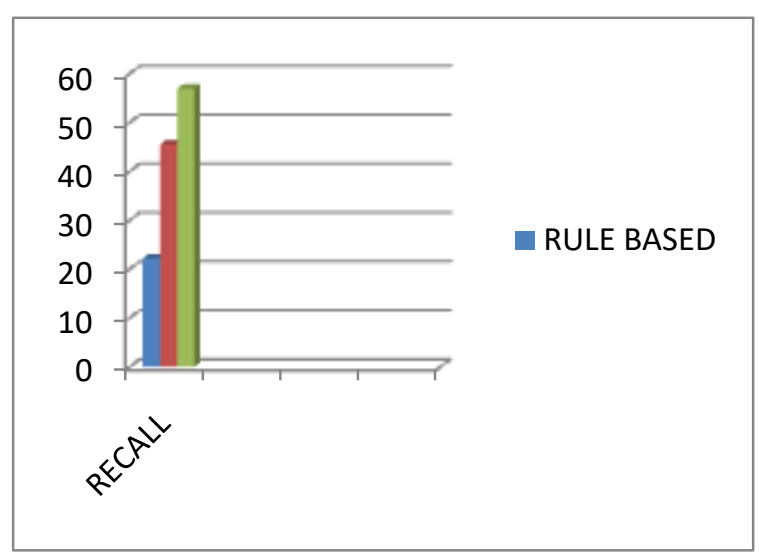

Figure - 14 Comparison of Recall of existing and proposed method

Figure 14 compares the Recall of the existing and proposed method. It can be seen that recall increases significantly when rule based and learning based approach is combined while detecting the product label

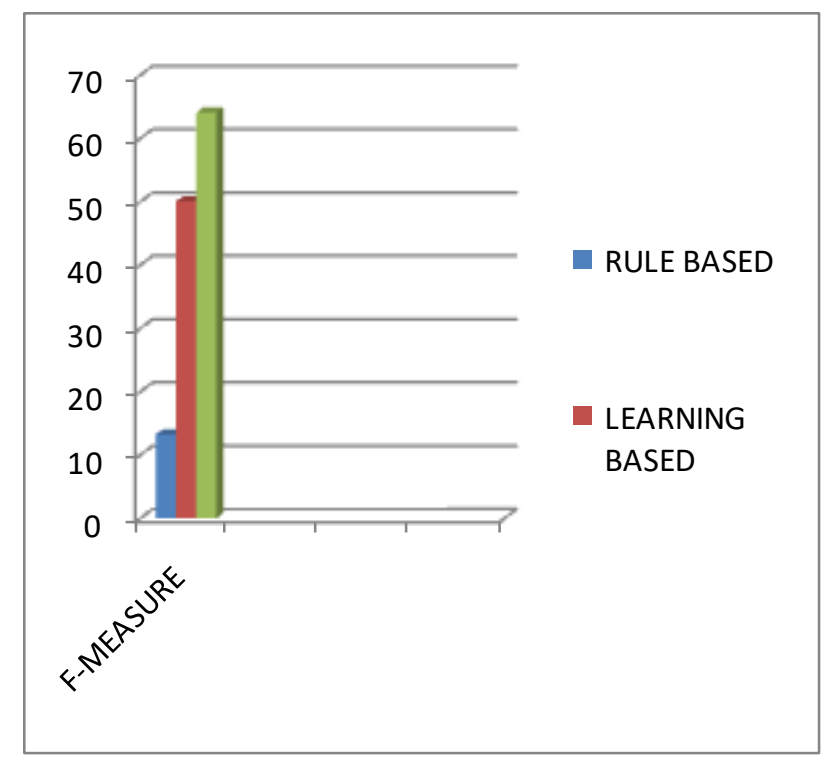

Figure 15 - Comparison of F-Measure of existing and

\section{CONCLUSION}

In this paper, we have depicted a model framework to peruse printed message on items for helping outwardly tested individuals. So as to take care of the regular centering issue for visually impaired clients, we have proposed a movement based technique to distinguish the object of intrigue, while the visually impaired client essentially moves the item for certain seconds. This strategy recognizes the object of enthusiasm from foundation or different articles which are in the camera see. Content is extricated from the moving item by utilizing two strategies one is rule-based and learning-based methods. Extricated content is converged into words and de-slanted so as to evacuate the arrangement issues. The content is digitalized utilizing OCR (Optical Character Recognition) and it is given to the client in type of discourse. Our future work can be stretched out to confinement calculation which can productively process content strings with less characters and spotlights on structuring hearty square designs for content component extraction. We will likewise stretch out our calculation to deal with non-level content strings. Moreover, we will address the significant human interface issues related with perusing content by visually impaired clients.

\section{REFERENCES}

1. Gowri Sankaran, B., Karthik, B. \& Vijayaragavan, S.P. 2019, "Weight ward change region plummeting change for square based image huffman coding", International Journal of Innovative Technology and Exploring Engineering, vol. 8, no. 10, pp. 4313-4316.

2. Gowri Sankaran, B., Karthik, B. \& Vijayaragavan, S.P. 2019, "Image compression utilizing wavelet transform", International Journal of Innovative Technology and Exploring Engineering, vol. 8, no. 10, pp. 4305-4308.

3. Kandavel, N. \& Kumaravel, A. 2019, "Offloading computation for efficient energy in mobile cloud computing", International Journal of Innovative Technology and Exploring Engineering, vol. 8, no. 10 , pp. $4317-4320$.

4. Vinoth, V.V. \& Kanniga, E. 2019, "Reversible data hiding in

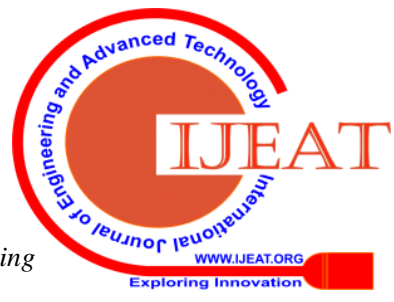


encrypting images-an system", International Journal of Engineering and Advanced Technology, vol. 8, no. 6, pp. 3051-3053.

5. Selvapriya, B. \& Raghu, B. 2019, "Pseudocoloring of medical images: A research", International Journal of Engineering and Advanced Technology, vol. 8, no. 6, pp. 3712-3716.

6. Senthil Kumar, K. \& Muthukumaravel, A. 2019, "Bi-objective constraint and hybrid optimizer for the test case prioritization", International Journal of Engineering and Advanced Technology, vol. 8, no. 6 , pp. 3436-3448.

7. Kavitha, G., Priya, N., Anuradha, C. \& Pothumani, S. 2019, "Read-write, peer-to-peer algorithms for the location-identity split", International Journal of Innovative Technology and Exploring Engineering, vol. 8, no. 9 Special Issue 3, pp. 445-447.

8. Kaliyamurthie, K.P., Michael, G., Anuratha, C. \& Sundaraj, B. 2019 "Certain improvements in alzheimer disease classification using nove fuzzy c means clustering for image segmentation", Internationa Journal of Innovative Technology and Exploring Engineering, vol. 8, no. 9 Special Issue 3, pp. 599-604.

9. Kaliyamurthie, K.P., Sundarraj, B., Geo, A.V.A. \& Michael, G. 2019 , "RIB: Analysis of I/O automata", International Journal of Innovative Technology and Exploring Engineering, vol. 8, no. 9 Special Issue 3, pp. 1019-1022.

10. Velvizhi, R., Rajabhushanam, C. \& Vidhya, S.R.S. 2019, "Opinion mining for travel route recommendation using Social Media Networks (Twitter)", International Journal of Innovative Technology and Exploring Engineering, vol. 8, no. 9 Special Issue 3, pp. 508-512.

11. Kavitha, R., Sangeetha, S. \& Varghese, A.G. 2019, "Human activity patterns in big data for healthcare applications", International Journal of Innovative Technology and Exploring Engineering, vol. 8, no. 9 Special Issue 3, pp. 1101-1103.

12. Pothumani, S., Anandam, A.K., Sharma, N. \& Franklin, S. 2019, "Extended VEOT framework - Implemented in a smart boutique", International Journal of Innovative Technology and Exploring Engineering, vol. 8, no. 9 Special Issue 3, pp. 762-767.

13. Kaliyamurthie, K.P., Michael, G., Krishnan, R.M.V. \& Sundarraj, B. 2019, "Pseudorandom techniques for the internet", International Journal of Innovative Technology and Exploring Engineering, vol. 8 , no. 9 Special Issue 3, pp. 915-918.

14. Aravindasamy, R., Jeffrin Rajan, M., Rama, A. \& Kavitha, P. 2019 "Deep learning provisions in the matlab: Focus on CNN facility", International Journal of Innovative Technology and Exploring Engineering, vol. 8, no. 9 Special Issue 3, pp. 990-994.

15. Theivasigamani, S., Linda, M. \& Amudha, S. 2019, "Object sensing and its identification \& motion sensing", International Journal of Innovative Technology and Exploring Engineering, vol. 8, no. 9 Special Issue 3, pp. 545-549.

16. Mary Linda, I., Vimala, D. \& Shanmuga Priya, K. 2019, "A methodology for the emulation of IPv4", International Journal of Innovative Technology and Exploring Engineering, vol. 8, no. 9 Special Issue 3, pp. 848-852.

17. Velvizhi, R., Priya, D.J., Vimala, D. \& Linda, I.M. 2019, "Increased routing algorithm for mobile adhoc networks", International Journal of Innovative Technology and Exploring Engineering, vol. 8, no. 9 Special Issue 3, pp. 1606-1608

18. Sangeetha, S., Anuradha, C. \& Priya, N. 2019, "DNS in real world", International Journal of Innovative Technology and Exploring Engineering, vol. 8, no. 9 Special Issue 3, pp. 937-940.

19. Geetha, C., Vimala, D. \& Priya, K.S. 2019, "Constructing multi-processors and spreadsheets with SKIVE", International Journal of Innovative Technology and Exploring Engineering, vol. 8, no. 9 Special Issue 3, pp. 516-519.

20. Yugendhar, K., Sugumar, V. \& Kavitha, P. 2019, "A novel method of univac using fuzzy logic", International Journal of Innovative Technology and Exploring Engineering, vol. 8, no. 9 Special Issue 3, pp. 435-437.

21. Kaliyamurthie, K.P., Michael, G., Elankavi, R. \& Jijo, S.A. 2019, "Implementing aggregate-key for sharing data in cloud environment using cryptographic encryption", International Journal of Innovative Technology and Exploring Engineering, vol. 8, no. 9 Special Issue 3, pp. 957-959.

22. Jeffrin Rajan, M., Aravindasamy, R., Kavitha, P. \& Rama, A. 2019, "A novel method of object orientation variation in $\mathrm{C}++$ and java", International Journal of Innovative Technology and Exploring Engineering, vol. 8, no. 9 Special Issue 3, pp. 708-710.

23. Nayak, R., Dinesh, S. \& Thirunavukkarasu, S. 2019, "A novel method improvement of rapid miner for the data mining applications", International Journal of Innovative Technology and Exploring Engineering, vol. 8, no. 9 Special Issue 3, pp. 457-460.
24. Sivaraman, K., Krishnan, R.M.V., Sundarraj, B. \& Sri Gowthem, S. 2019, "Network failure detection and diagnosis by analyzing syslog and SNS data: Applying big data analysis to network operations", International Journal of Innovative Technology and Exploring Engineering, vol. 8, no. 9 Special Issue 3, pp. 883-887.

25. Vimala, D., Linda, I.M. \& Priya, K.S. 2019, "Decoupling online algorithms from erasure coding in DNS", International Journal of Innovative Technology and Exploring Engineering, vol. 8, no. 9 Special Issue 3, pp. 950-953

26. Rama, A., Kumaravel, A. \& Nalini, C. 2019, "Preprocessing medical images for classification using deep learning techniques", International Journal of Innovative Technology and Exploring Engineering, vol. 8 , no. 9 Special Issue 3, pp. 711-716.

27. Sangeetha, S., Srividhya, S.R., Anita Davamani, K. \& Amudha, S 2019, "A procedure for avoid overrun error in universal synchronous asynchronous receiver transmitter (usart) by utilizing dummy join and interrupt latency method", International Journal of Innovative Technology and Exploring Engineering, vol. 8, no. 9 Special Issue 3, pp. 657-660.

28. Aravindasamy, R., Jeyapriya, D., Sundarajan, B. \& Sangeetha, S. 2019, "Data duplication in cloud for optimal performance and security", International Journal of Innovative Technology and Exploring Engineering, vol. 8, no. 9 Special Issue 3, pp. 1156-1158

29. Aravindasamy, R., Jeffrin Rajan, M., Sugumar, V. \& Kavitha, P. 2019, "A novel method on developing superblocks and the transistor using apodryal", International Journal of Innovative Technology and Exploring Engineering, vol. 8, no. 9 Special Issue 3, pp. 982-985.

30. Sasikumar, C.S. \& Kumaravel, A. 2019, "E-learning attributes selection through rough set theory and data mining", International Journal of Innovative Technology and Exploring Engineering, vol. 8, no. 10 , pp. 3920-3924

\section{AUTHORS PROFILE}

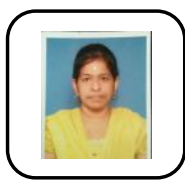

S.Jeyapriyanga Assistant Professor, Department of Computer science and Engineering, Bharath Institute of Higher Education and Research, Chennai, India

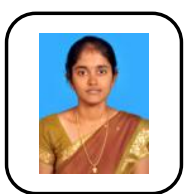

S.P.Priyadharshini Assistant Professor, Department of Computer science and Engineering, Bharath Institute of Higher Education and Research, Chennai, India

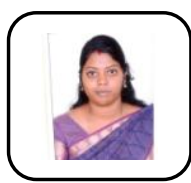

Sangeetha S Assistant Professor, Department of Computer science and Engineering, Bharath Institute of Higher Education and Research, Chennai, India 